ARTICLE

https://doi.org/10.1038/s41467-020-18425-5

\title{
Elucidating the role of metal ions in carbonic anhydrase catalysis
}

Jin Kyun Kim (1) ${ }^{1}$, Cheol Lee (10 ${ }^{1}$, Seon Woo Lim¹, Aniruddha Adhikari', Jacob T. Andring ${ }^{2}$, Robert McKenna ${ }^{2}$, Cheol-Min Ghim (i) ${ }^{1} \&$ Chae Un Kim (i) ${ }^{1 凶}$

Why metalloenzymes often show dramatic changes in their catalytic activity when subjected to chemically similar but non-native metal substitutions is a long-standing puzzle. Here, we report on the catalytic roles of metal ions in a model metalloenzyme system, human carbonic anhydrase II (CA II). Through a comparative study on the intermediate states of the zincbound native CA II and non-native metal-substituted CA IIs, we demonstrate that the characteristic metal ion coordination geometries (tetrahedral for $\mathrm{Zn}^{2+}$, tetrahedral to octahedral conversion for $\mathrm{Co}^{2+}$, octahedral for $\mathrm{Ni}^{2+}$, and trigonal bipyramidal for $\mathrm{Cu}^{2+}$ ) directly modulate the catalytic efficacy. In addition, we reveal that the metal ions have a long-range $(\sim 10 \AA)$ electrostatic effect on restructuring water network in the active site. Our study provides evidence that the metal ions in metalloenzymes have a crucial impact on the catalytic mechanism beyond their primary chemical properties.

\footnotetext{
${ }^{1}$ Department of Physics, Ulsan National Institute of Science and Technology (UNIST), Ulsan 44919, Republic of Korea. ${ }^{2}$ Department of Biochemistry and Molecular Biology, College of Medicine, University of Florida, Gainesville, FL 32610, USA. ${ }^{凶}$ email: cukim@unist.ac.kr
} 
$\mathrm{M}$ etalloproteins are ubiquitous in nature and play indispensable roles in key biological processes, such as DNA synthesis, chemical signaling, and cellular metabolism ${ }^{1,2}$. Due to their versatile chemical reactivity (acidity, electrophilicity, and/or nucleophilicity), incorporated metal ions add functionality to proteins and help catalyze some of the most intricate reactions in nature ${ }^{3,4}$. The issues of metal binding affinity and specificity of metal ions to proteins have been studied based on the metal coordination stereochemistry ${ }^{5,6}$ and semiempirical and qualitative theories such as hard and soft acids and bases principle of Parr and Pearson ${ }^{7}$ and Irving-Williams series of divalent ion stability ${ }^{8,9}$. However, the role of metal ions in the functioning of proteins and the metal-protein relationships remain unclear at the atomic level. For example, metalloenzymes substituted by non-native metal ions often exhibit drastically different catalytic activities ${ }^{10,11}$, even when the substituted metal ions show chemical features broadly similar to the native one, such as ionic charge/size/mass, redox potential, electronic configuration, and allowed coordination geometry.

Among the various types of metalloenzymes, carbonic anhydrase (CA), the first enzyme recognized to contain zinc, is ubiquitous across all kingdoms of life and one of the most catalytically efficient enzymes ever known ${ }^{12-16}$. The enzyme catalyzes the reversible hydration of carbon dioxide $\left(\mathrm{CO}_{2}\right)$ and thereby plays a critical role in respiration, particularly in the $\mathrm{CO}_{2}$ transport by way of blood-dissolved bicarbonate $\left(\mathrm{HCO}_{3}{ }^{-}\right)$, and in intracellular $\mathrm{pH}$ homeostasis by maintaining $\mathrm{CO}_{2} / \mathrm{HCO}_{3}{ }^{-}$equilibrium. Within the wide classes of CA, CA II from human is well-suited to serve as a model system for investigating the role of metal ions because its overall structure is well-refined with atomic resolution $(\sim 1.0 \AA)$. It possesses a well-defined active site containing a single metal-binding site (Fig. 1a, b), and the kinetic rates and fine details of the enzymatic mechanism have been studied extensively ${ }^{17-21}$ (Fig. 1c).

The active site of CA II is located at the base cavity of a $15 \AA$ depth from the surface and is further subdivided into three regions comprised of hydrophobic and hydrophilic regions, with an entrance conduit (EC) in-between ${ }^{22-25}$ (Fig. 1a). These regions are responsible for substrate binding, proton transfer, and substrate/product/water exchange during catalysis, respectively (Fig. 1b). The active site zinc ion is tetrahedrally coordinated to the protein by the imidazole groups of three histidine residues, with the remaining tetrahedral site occupied by a solvent molecule (water or hydroxide ion, depending upon $\mathrm{pH}$ ). The catalytic zinc ion in CA II serves as a Lewis acid; its primary role is to lower the $\mathrm{p} K_{\mathrm{a}}$ of the $\mathrm{Zn}$-bound water from 10 to 7 , allowing the formation of a zinc-bound hydroxide ion at physiological $\mathrm{pH}^{26}$. The zinc ion can be substituted by other physiologically relevant transition metal ions such as $\mathrm{Co}^{2+}, \mathrm{Ni}^{2+}, \mathrm{Cu}^{2+}, \mathrm{Cd}^{2+}$, and $\mathrm{Mn}^{2+}$ which results in drastic changes in the catalytic activity of CA II $(\sim 50 \% \text { active to completely inactive })^{21}$. It has been also reported that the metal substitutions may induce alternative catalytic activities of CA II other than $\mathrm{CO}_{2} / \mathrm{HCO}_{3}{ }^{-}$conversion ${ }^{27}$, for instance, reduction of nitrite to nitric oxide in presence of copper $^{28}$.

Previous structural studies had suggested that different metal coordination geometries in the non-native CA II may play an important role in their catalysis ${ }^{29,30}$, but no clear evidence was presented to support such a claim. Our present study focuses on investigating the detailed structural changes in CA II during the $\mathrm{CO}_{2} / \mathrm{HCO}_{3}{ }^{-}$conversion catalysis and correlating these variations to the relevant catalytic mechanisms. These experimental insights a

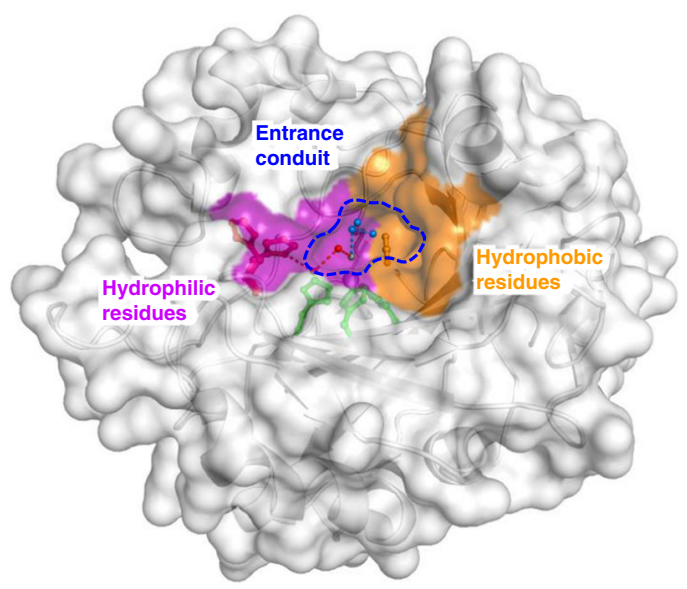

b

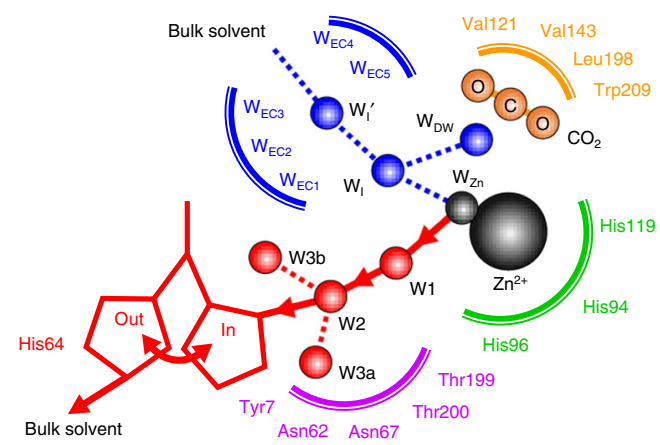

C

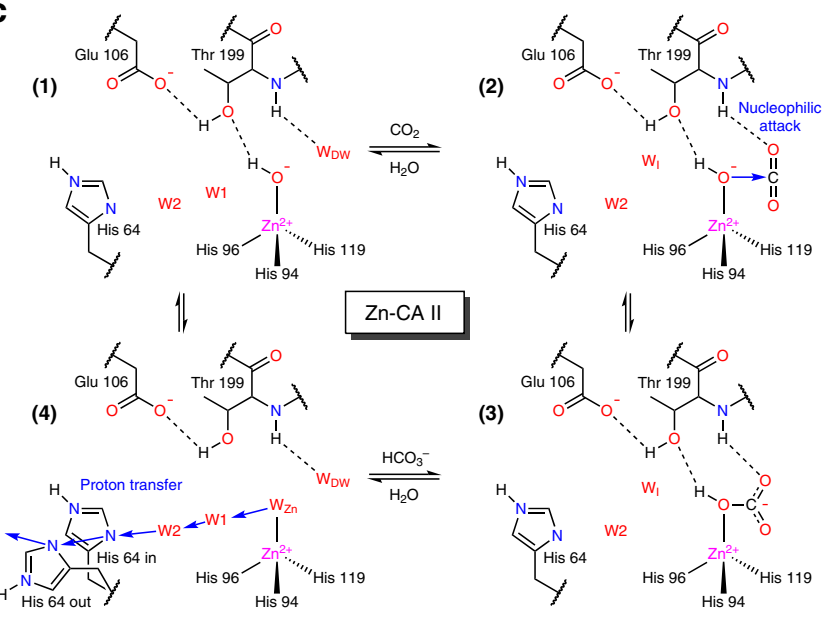

Fig. 1 Structure of native carbonic anhydrase II (Zn-CA II) and its catalytic mechanism. a The active site consists of zinc binding site, hydrophobic/hydrophilic regions, and entrance conduit (EC). b The water networks in the active site are responsible for the proton transfer (red) and substrate/product/water exchange (blue) during enzyme catalysis. c The $\mathrm{CO}_{2}$ hydration reaction mechanism of $\mathrm{Zn}-\mathrm{CA} \mathrm{II}$. First, $\mathrm{CO}_{2}$ binds to the active site, leading to a nucleophilic attack by the zinc-bound hydroxyl ion onto $\mathrm{CO}_{2} . \mathrm{HCO}_{3}$ - thus formed is subsequently displaced by the water molecule inflowing through EC. The $\mathrm{HCO}_{3}{ }^{-}$molecule likely binds to $\mathrm{Zn}^{2+}$ ion in a monodentate mode and its $\mathrm{OH}$ group is held at the $\mathrm{Zn}^{2+}$ ion due to the hydrogen bonding with Thr19952,53. This product binding configuration leads to a weak interaction between the product and $\mathrm{Zn}^{2+}$ ion, thereby facilitating fast product dissociation ${ }^{54}$. Finally, proton transfer occurs via the network $\left(\mathrm{W}_{\mathrm{Zn}} \rightarrow \mathrm{W} 1 \rightarrow \mathrm{W} 2 \rightarrow\right.$ His64) provided by the protein scaffold. 
a

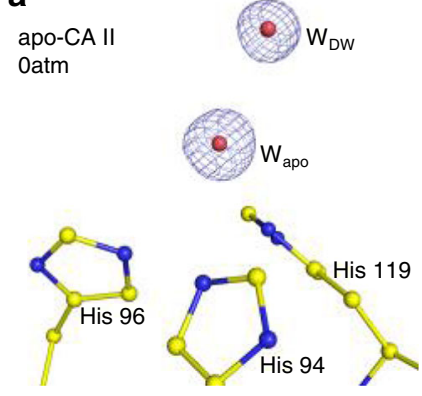

b

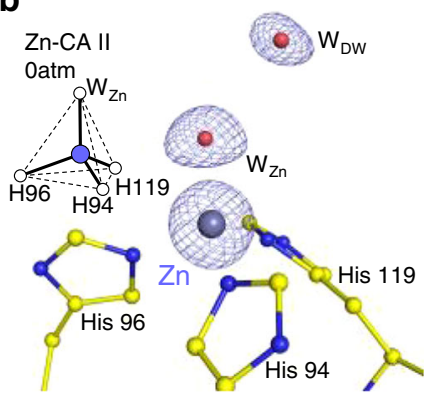

d

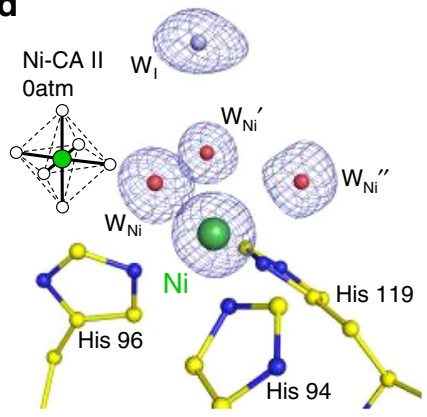

C

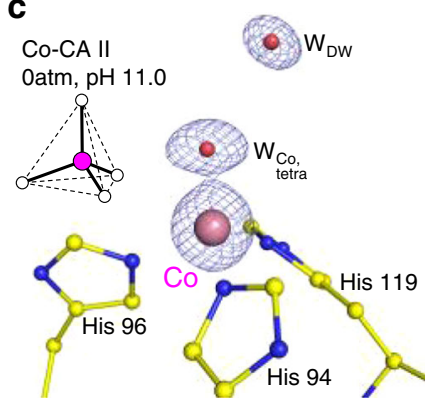

e

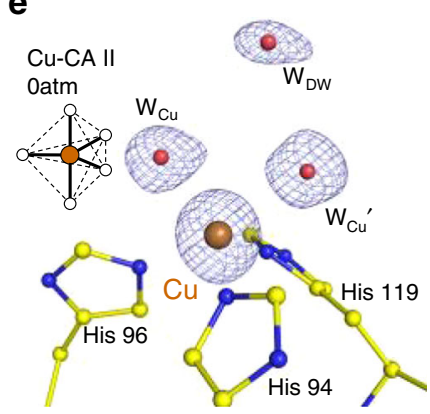

Fig. 2 Metal coordination geometry in CA II without $\mathbf{C O}_{\mathbf{2}}$ pressurization. a In apo-CA II, the metal binding site is vacant. $\mathbf{b}$, $\mathbf{c} \mathrm{Zn}$ - and $\mathrm{Co}-\mathrm{CA}$ II show tetrahedral, $\mathbf{d} \mathrm{Ni}-\mathrm{CA}$ II octahedral, and e Cu-CA II trigonal bipyramidal coordination geometry. The electron density ( $2 \mathrm{~F}_{\mathrm{o}}-\mathrm{F}_{\mathrm{c}}$, blue) is contoured at $2.2 \sigma$. All structures were obtained at $\mathrm{pH} 7.8$ except for $(\mathbf{c})$ which is obtained at $\mathrm{pH} 11.0$. The intermediate water $\left(\mathrm{W}_{1}\right)$ in $(\mathbf{d})$ is colored in steel blue for clarity.

offer us a fresh peek into the origin of the activity alterations caused by non-native metal substitutions.

To study the role of metal ions in CA II, we selected four divalent transition-metal ions $\left(\mathrm{Zn}^{2+}, \mathrm{Co}^{2+}, \mathrm{Ni}^{2+}\right.$, and $\left.\mathrm{Cu}^{2+}\right)$ that induce drastic changes in CA II activity $(100 \%, \sim 50 \%, \sim 2 \%$, and $0 \%$, respectively $)^{31,32}$. The catalytic intermediate states of the metal-free (apo, as a control) and the four metal-bound CA IIs were prepared by cryocooling protein crystals under $\mathrm{CO}_{2}$ pressures from 0 (no $\mathrm{CO}_{2}$ pressurization) to $20 \mathrm{~atm}^{33,34}$.

We show that the characteristic metal ion coordination geometries directly modulate the catalytic processes, including substrate binding, its conversion to product, and product binding. In addition, we reveal that the metal ions have a long-range $(\sim 10 \AA)$ electrostatic effect on restructuring the water network at the active site, affecting the product displacement and the proton transfer process. The cumulative effect of such alterations provides mechanistic insights into the overall reduction of the enzymatic activity in the non-native metal-substituted CA IIs.

\section{Results}

The role of metal ion coordination geometries. The coordination geometry around the metal binding site in CA II, when no $\mathrm{CO}_{2}$ pressure is applied, is shown in Fig. 2. The metal-free apoCA II shows an electron density map reflecting the presence of a water molecule in the metal binding site (Fig. 2a). In Zn-CA II and Co-CA II ( $\mathrm{pH} 11.0)$, the metal ions display tetrahedral coordination with three histidine residues (His94, His96, and His119) and a water molecule (Fig. 2b, c). In contrast, Ni-CA II contains three bound water molecules, completing an octahedral (hexa-coordinate) geometry (Fig. 2d). Finally, Cu-CA II possesses two bound water molecules, arranged in trigonal bipyramidal (penta-coordinate) geometry (Fig. 2e).

Next, we investigated the effect of metal coordination geometry on the efficacy of substrate $\left(\mathrm{CO}_{2}\right)$ and product $\left(\mathrm{HCO}_{3}{ }^{-}\right)$binding. The apo- and $\mathrm{Zn}-\mathrm{CA}$ II structures cryocooled at $20 \mathrm{~atm} \mathrm{CO}_{2}$ pressure are shown in Fig. 3. The apo-CA II shows a clear binding a

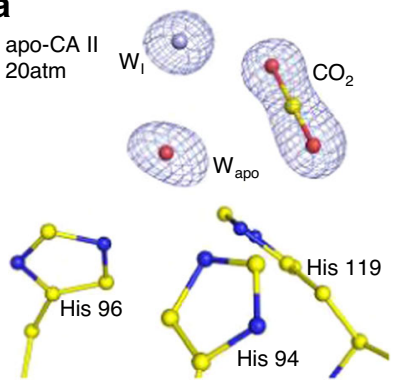

b

C

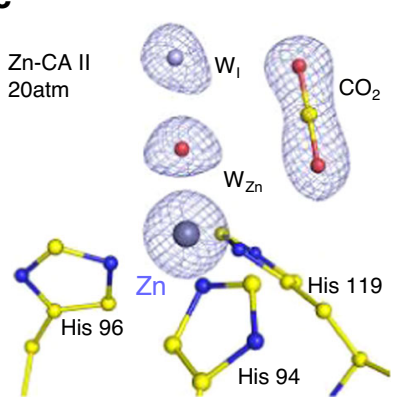

d

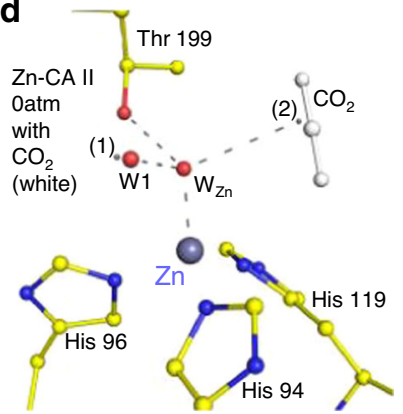

Fig. 3 Substrate/product binding in apo- and Zn-CA II. The intermediate water $\left(\mathrm{W}_{1}\right)$ is colored in steel blue for clarity. The electron density $\left(2 \mathrm{~F}_{\mathrm{o}}-\mathrm{F}_{\mathrm{c}}\right.$ blue) is contoured at $2.2 \sigma$. $\mathbf{a}, \mathbf{b}$ At 20 atm of $\mathrm{CO}_{2}$ pressure, apo-CA II shows clear binding of $\mathrm{CO}_{2}$ without the need of $\mathrm{Zn}^{2+}$ ion. $\mathbf{~} \mathrm{Zn}$-CA II shows similar binding of $\mathrm{CO}_{2}$ as in apo-CA II while maintaining tetrahedral metal coordination. $\mathbf{d}$ Upon $\mathrm{CO}_{2}$ binding (white) in $\mathrm{Zn}-\mathrm{CA} \mathrm{II}, \mathrm{W}_{\mathrm{Zn}}$ is located at the center of the hypothetical tetrahedral arrangement made up of $\mathrm{Zn}^{2+}$ ion, Thr199-O $\gamma 1$, position (1) (close to W1), and position (2) (close to the carbon atom in $\mathrm{CO}_{2}$ ). In this configuration, a hybridized lone pair in $\mathrm{W}_{\mathrm{Zn}}$ directly faces $\mathrm{CO}_{2}$ molecule at a distance, appropriate for efficient nucleophilic attack. Distance between the position (2) and $\mathrm{C}$ atom of $\mathrm{CO}_{2}$ is merely $0.36 \AA$. 
a

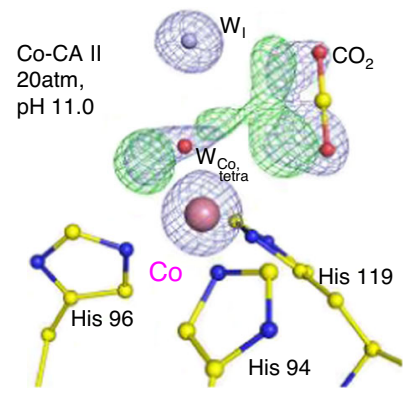

C

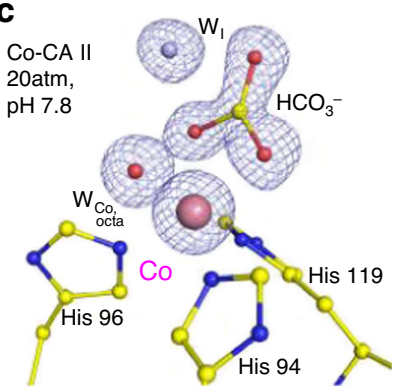

b

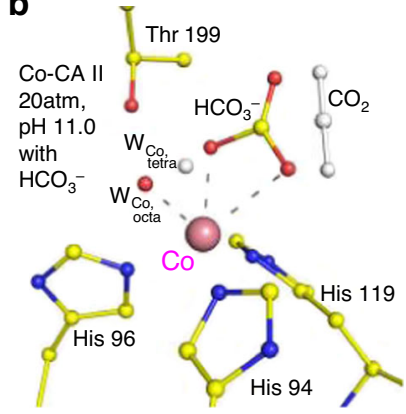

d

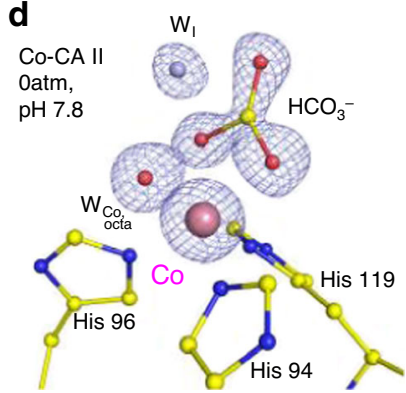

Fig. 4 Substrate/product binding in Co-CA II. The intermediate water $\left(W_{1}\right)$ is colored in steel blue for clarity. The electron density $\left(2 F_{0}-F_{c}\right.$, blue $)$ and the difference map $\left(\mathrm{F}_{\mathrm{o}}-\mathrm{F}_{\mathrm{c}}\right.$, green $)$ are contoured at $2.2 \sigma$ and $7.0 \sigma$, respectively. a, b At $20 \mathrm{~atm}$ of $\mathrm{CO}_{2}$ pressure, Co-CA II at pH 11.0 shows superposition of $\mathrm{CO}_{2}$ binding ( $50 \%$ occupancy, white) with tetrahedral coordination and $\mathrm{HCO}_{3}{ }^{-}$binding ( $50 \%$ occupancy) with octahedral coordination. c, d Co-CA II at pH 7.8 shows complete binding of $\mathrm{HCO}_{3}{ }^{-}$, showing octahedral coordination even in absence of added $\mathrm{CO}_{2}$. It is likely that the captured $\mathrm{HCO}_{3}-$ is converted from the $\mathrm{CO}_{2}$ absorbed in the crystal from ambient air.

of $\mathrm{CO}_{2}$ molecule, replacing deep water, $\mathrm{W}_{\mathrm{DW}}$ present within the active site, suggesting that the $\mathrm{CO}_{2}$ binding at the active site is mostly dictated by the metal-free protein scaffold (Fig. 3a). The native holoenzyme $\mathrm{Zn}$-CA II shows $\mathrm{CO}_{2}$ binding almost identical to that in apo-CA II (Fig. 3b, c). The $\mathrm{CO}_{2}$ molecule is located 2.9 $\AA$ away from the $\mathrm{Zn}$-bound water $\left(\mathrm{W}_{\mathrm{Zn}}\right)$, in a configuration conducive for the nucleophilic attack (Fig. 3d).

In Co-CA II ( $\mathrm{pH} 11.0$ ) cryocooled at 20 atm $\mathrm{CO}_{2}$ pressure, dual binding of $\mathrm{CO}_{2}$ and $\mathrm{HCO}_{3}{ }^{-}$is observed (Fig. 4a). Upon $\mathrm{CO}_{2}$ binding, the tetrahedral coordination is maintained, but an unusual expansion to octahedral coordination is observed upon $\mathrm{HCO}_{3}{ }^{-}$binding (Fig. 4b). In the transformed octahedral geometry, the $\mathrm{HCO}_{3}{ }^{-}$molecule is bound in a bidentate mode to the $\mathrm{Co}^{2+}$ ion along with an additional water molecule. Compared to the monodentate binding mode in $\mathrm{Zn}-\mathrm{CA}$ II, the negative charge on the bidentate $\mathrm{HCO}_{3}{ }^{-}$can be distributed among the two oxygen atoms bound to $\mathrm{Co}^{2+}$ ion, allowing stronger product binding to the metal ion (Supplementary Fig. 1a-f). Unlike Zn-CA II (Supplementary Fig. 2), the Co-CA II intermediates obtained at different $\mathrm{pH}$ values (7.8 and 11.0) reveal that the $\mathrm{HCO}_{3}{ }^{-}$molecule is firmly bound to $\mathrm{Co}^{2+}$ ion with full occupancy at lower $\mathrm{pH}$ (Fig. 4c, d), but this binding affinity weakens as $\mathrm{pH}$ increases (Fig. 4a). The result suggests that, during the catalytic cycle, deprotonation of the $\mathrm{Co}^{2+}$-bound water may lead to dissociation of the $\mathrm{HCO}_{3}{ }^{-}$molecule from the $\mathrm{Co}^{2+}$ ion, due to the charge-charge repulsion between the formed hydroxide ion and the $\mathrm{HCO}_{3}{ }^{-}$molecule. Following the $\mathrm{HCO}_{3}{ }^{-}$ dissociation, the tetrahedral coordination is restored (Fig. 2c).

On the other hand, at $20 \mathrm{~atm} \mathrm{CO}_{2}$ pressure, Ni-CA II shows octahedral coordination comprising the bidentate $\mathrm{HCO}_{3}{ }^{-}$and a

a

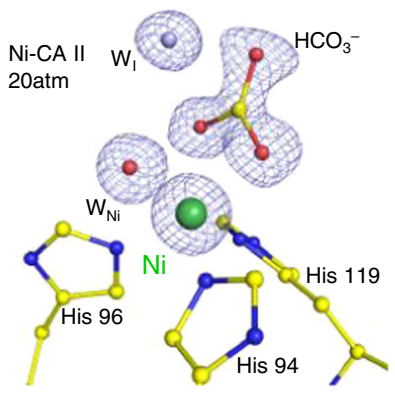

b

C

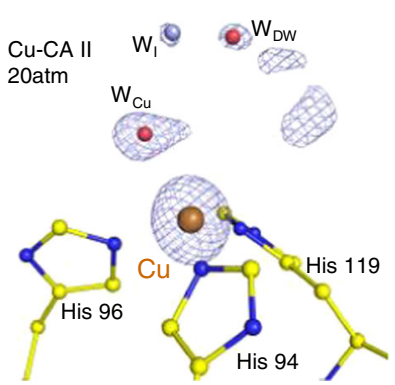

d

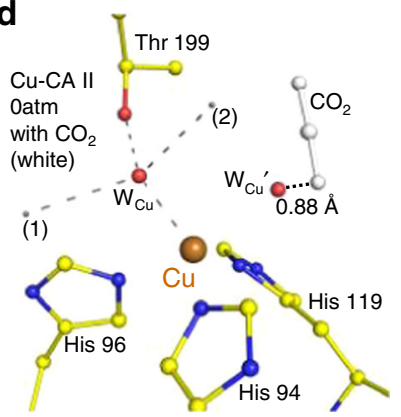

Fig. 5 Substrate/product binding in Ni- and Cu-CA II. The intermediate water $\left(\mathrm{W}_{1}\right)$ is colored in steel blue for clarity. The electron density $\left(2 \mathrm{~F}_{\mathrm{o}}-\mathrm{F}_{\mathrm{C}_{1}}\right.$ blue) is contoured at $2.2 \sigma$. a At 20 atm of $\mathrm{CO}_{2}$ pressure, Ni-CA II maintains octahedral coordination with $\mathrm{HCO}_{3}$ - binding. $\mathbf{b}$ Compared to the $\mathrm{W}_{\mathrm{Zn}}$ geometry in Zn-CA II (Fig. 3d), the nucleophilic attack geometry around $\mathrm{W}_{\mathrm{Ni}}{ }^{\prime}$ has steric hindrance on $\mathrm{CO}_{2}$ molecule (adapted from $\mathrm{Zn}-\mathrm{CA}$ II, $20 \mathrm{~atm}$, white) and is distorted away. Distance between the position (2) and $\mathrm{C}$ atom of $\mathrm{CO}_{2}$ is $1.55 \AA$. c $\mathrm{Cu}-\mathrm{CA}$ II shows only disordered electron density in the $\mathrm{CO}_{2} / \mathrm{HCO}_{3}-$ binding site. $\mathbf{d}$ The nucleophilic attack geometry around $\mathrm{W}_{\mathrm{Cu}}$ has steric hindrance on $\mathrm{CO}_{2}$ molecule (adapted from $\mathrm{Zn}-\mathrm{CA}$ II, $20 \mathrm{~atm})$ and is significantly distorted away. Distance between the position (2) and $\mathrm{C}$ atom of $\mathrm{CO}_{2}$ is $2.93 \AA$.

water molecule in a similar manner to that of Co-CA II (Fig. 5a, Supplementary Fig. $1 \mathrm{~g}-\mathrm{i}$ ). It is noted that one of the three bound water molecules experiences steric hindrance with the $\mathrm{CO}_{2}$ binding configuration in Zn-CA II (Fig. 5b). Thus, it is likely that the $\mathrm{CO}_{2}$ molecule entering the active site pushes away one of the Ni-bound water molecules, and then a nucleophilic attack occurs from one of the two remaining water molecules, forming $\mathrm{HCO}_{3}{ }^{-}$. Unlike Co-CA II (Fig. 4a, c, d), the Ni-CA II intermediates obtained at different $\mathrm{pH}$ values (7.8 and 11.0) indicate that the $\mathrm{HCO}_{3}{ }^{-}$binding affinity is almost unresponsive to $\mathrm{pH}$ variation (Supplementary Fig. 3). The result suggests that the deprotonation of the $\mathrm{Ni}^{2+}$-bound water is insufficient to facilitate $\mathrm{HCO}_{3}{ }^{-}$ dissociation in the stable octahedral coordination, and that the bound $\mathrm{HCO}_{3}{ }^{-}$is directly displaced by two incoming water molecules in Ni-CA II. Finally, in Cu-CA II, no clear electron density of $\mathrm{CO}_{2}$ or $\mathrm{HCO}_{3}^{-}$is visible (Fig. $5 \mathrm{c}$ ). The faint and diffused electron density suggests that a $\mathrm{CO}_{2}$ molecule encounters a severe steric hindrance from one of $\mathrm{Cu}^{2+}$-bound water molecules. Even if the $\mathrm{CO}_{2}$ molecule adopts proper orientation as in $\mathrm{Zn}-\mathrm{CA}$ II, the bound $\mathrm{CO}_{2}$ position remains far too distant $(3.9 \AA)$ from the spare $\mathrm{Cu}^{2+}$-bound water molecule for any effective interaction. Moreover, the significantly distorted geometry negates the scope of any nucleophilic attack (Fig. 5d). The inefficient substrate binding and the unfavorable distorted geometry explain the complete enzymatic inactivity of $\mathrm{Cu}-\mathrm{CA}$ II.

Electrostatic effects of metal ions on active-site water network. Figure 6 shows the proton transfer pathway and the water 
a

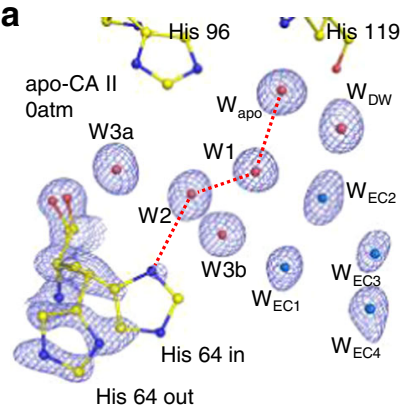

C

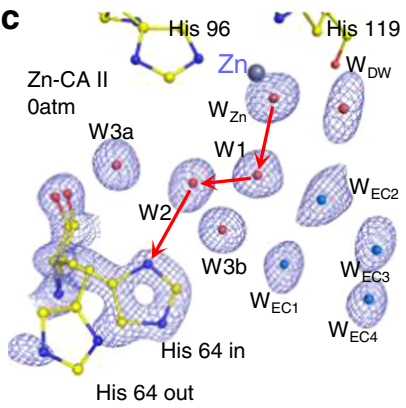

e

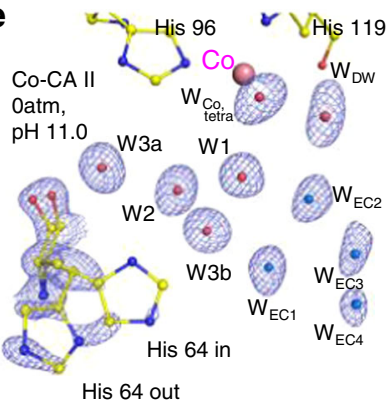

g
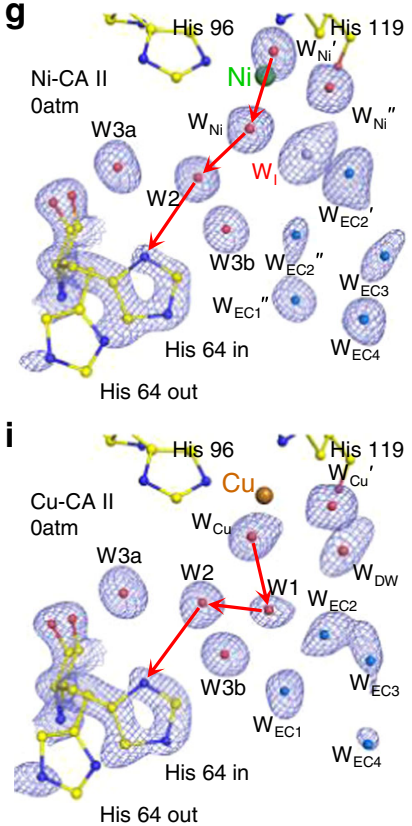
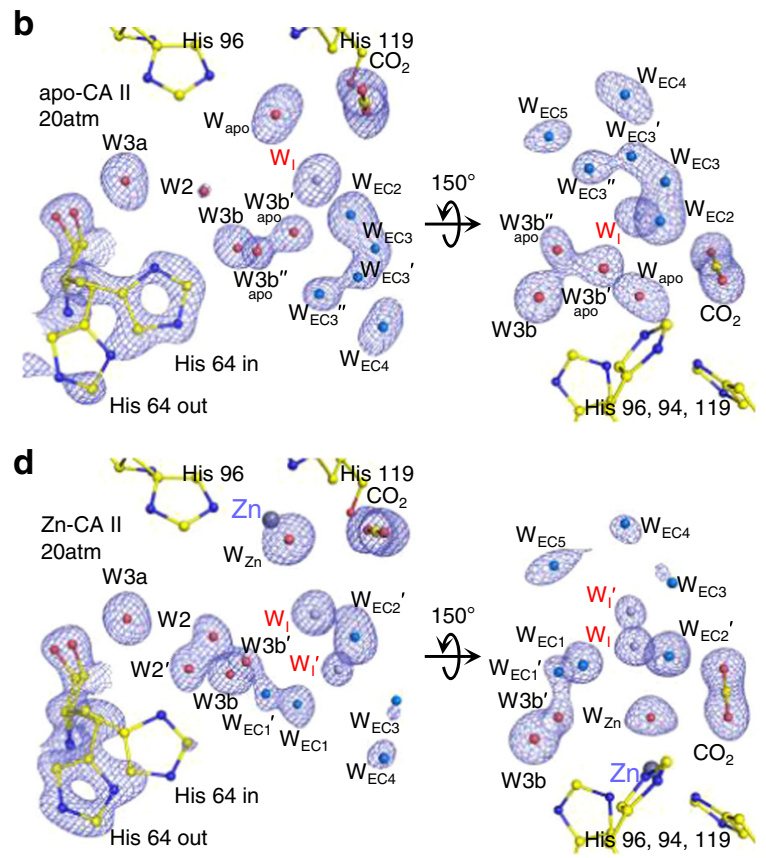

f

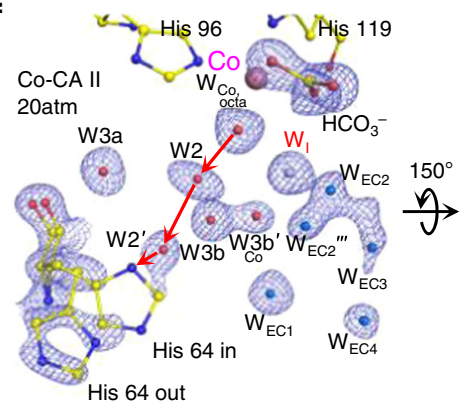

h
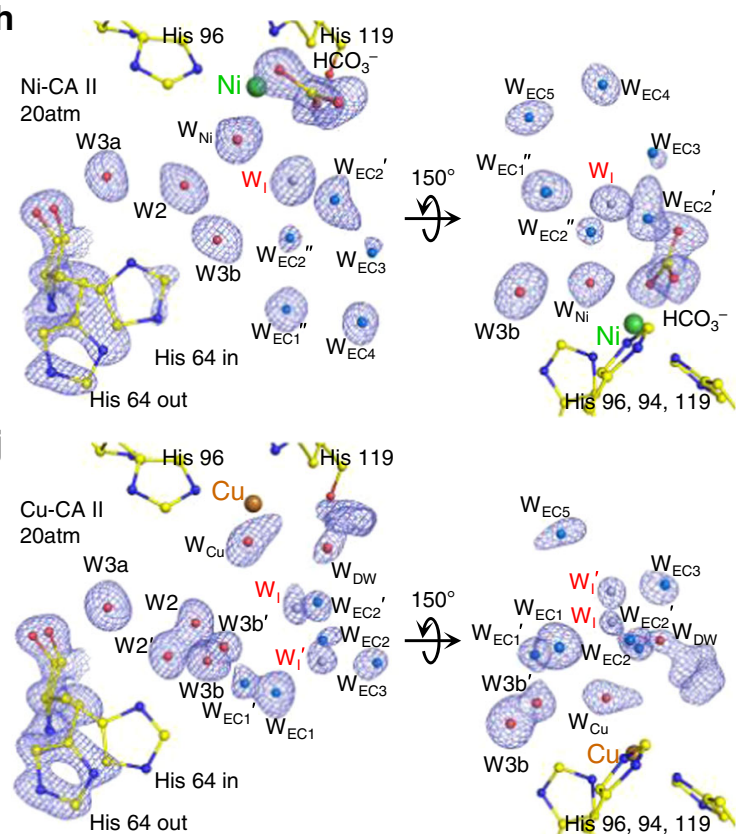
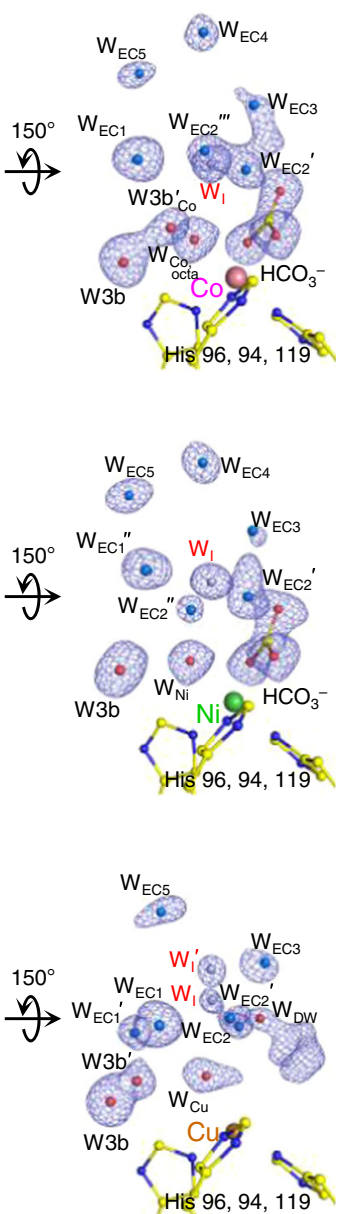

network in the EC of CA II. The metal-free apo-CA II shows the well-defined pathway $\left(\mathrm{W}_{\mathrm{Apo}} \rightarrow \mathrm{W} 1 \rightarrow \mathrm{W} 2 \rightarrow\right.$ His64, Fig. 6a) in the absence of $\mathrm{CO}_{2}$. Upon $\mathrm{CO}_{2}$ binding, the pathway is disrupted in such a way that $\mathrm{W} 1$ disappears and an intermediate water $\mathrm{W}_{\mathrm{I}}$ emerges (Figs. 3a and 6b). Zn-CA II largely resembles the apoenzyme in terms of both the same well-defined pathway
$\left(\mathrm{W}_{\mathrm{Zn}} \rightarrow \mathrm{W} 1 \rightarrow \mathrm{W} 2 \rightarrow\right.$ His64) utilized for proton transfer (Fig. 6c) and the dynamics of $\mathrm{W} 1 / \mathrm{W}_{\mathrm{I}}$ upon $\mathrm{CO}_{2}$ binding (Figs. $3 \mathrm{c}$ and $6 \mathrm{~d}$ ). This observation clearly suggests that the primary water network necessary for the proton transfer is organized by the protein scaffold without the need for metal ions. However, in comparison to apo-CA II (Fig. 6b), Zn-CA II shows significantly 
Fig. 6 Active site in CA II showing proton transfer pathway and EC water network $\left(\mathbf{W}_{\mathbf{E C 1}} \sim \mathbf{W}_{\mathbf{E C 5}}\right)$. The electron density $\left(2 \mathrm{~F}_{\mathrm{o}}-\mathrm{F}_{\mathrm{C}}\right)$ is contoured at $1.7 \sigma$ except for EC waters at 1.5\%. The EC waters are colored in aqua marine and the intermediate waters $\left(W_{1}\right.$ and $\left.W_{1}^{\prime}\right)$ in steel blue for clarity. $W 2^{\prime}$ is an alternative position of W2. The possible proton transfer pathways in the metal-CA Ils are depicted as red arrows. All structures were obtained at $\mathrm{pH} 7.8$ except for $\mathbf{e}$ at $\mathrm{pH}$ 11.0. a, b Apo-CA II shows well-ordered water arrangement (dotted red line) with His64 favored in outward conformation at 0 atm $\mathrm{CO}_{2}$ pressure. Upon $\mathrm{CO}_{2}$ binding, His64 moves inward and water molecules show highly dynamical motions, stabilizing $\mathrm{W}_{1}$. c, d Zn-CA II shows His64 favored in inward conformation at $\mathrm{O} \mathrm{atm} \mathrm{CO}_{2}$ pressure. Upon $\mathrm{CO}_{2}$ binding, $\mathrm{W} 2, \mathrm{~W} 3 \mathrm{~b}$, and $\mathrm{W}_{\mathrm{EC}}$ waters show significantly different dynamics with His64 moving outward, and an additional intermediate water $\left(W_{1}{ }^{\prime}\right)$ is stabilized with the $W_{E C}$ molecules. The motions of $W 3 b$ and $W_{E C 1}$ turn on the dynamic interplay between the proton transfer and EC water networks. e, f Co-CA II shows similar arrangement initially as in $\mathrm{Zn}-\mathrm{CA}$ II. However, upon full $\mathrm{HCO}_{3}{ }^{-}$binding, the dynamical motions of EC waters are different and the intermediate water $W_{1}^{\prime}$ is less stabilized. Note that, in Co-CA II, proton transfer seems to occur while the product is still bound. $\mathbf{g}, \mathbf{h} \mathrm{Ni}-\mathrm{CA}$ II initially shows altered water arrangements due to octahedral coordination. Upon $\mathrm{HCO}_{3}-$ binding, significantly reduced water dynamical motions are recognized. $\mathbf{i}, \mathbf{j}$ Cu-CA II shows unexpectedly similar dynamical motions of active site waters and His64 as in Zn-CA II.

modified dynamics of W2 and His64, which are believed to be critical for efficient proton transfer (Fig. 6d). Additionally, in ZnCA II, the significantly modified dynamics of the EC waters stabilizes another intermediate water $\mathrm{W}_{\mathrm{I}}{ }^{\prime}$, that in turn bridges $\mathrm{W}_{\mathrm{I}}$ with the bulk solvent outside the protein, thereby facilitating the replenishment of $\mathrm{W}_{\mathrm{Zn}}$ and $\mathrm{W} 1$ during the catalytic cycle (Figs. $1 \mathrm{~b}$ and $6 \mathrm{~d}$ ). These observations suggest that the $\mathrm{Zn}^{2+}$ ion produces a long-range $(\sim 10 \AA)$ electrostatic field in which water structure and dynamics in the active site are fine-tuned to facilitate the proton transfer and the water/substrate/product exchange.

In the absence of $\mathrm{CO}_{2}$, Co-CA II forms the same proton transfer network as in $\mathrm{Zn}$-CA II (Fig. 6e). Once $\mathrm{CO}_{2}$ or $\mathrm{HCO}_{3}{ }^{-}$ binds, $\mathrm{W} 1$ disappears and $\mathrm{W}_{\mathrm{I}}$ appears like what happens in $\mathrm{Zn}$ CA II (Figs. 4a, c, and 6f). However, as the deprotonation of $\mathrm{Co}^{2+}$-bound water should occur prior to the $\mathrm{HCO}_{3}{ }^{-}$dissociation, it is likely that the proton transfer occurs via the altered network $\left(\mathrm{W}_{\text {Co,octa }} \rightarrow \mathrm{W} 2 \rightarrow\right.$ His64) while the product is still bound to the $\mathrm{Co}^{2+}$ ion (Fig. 6f). In addition, Co-CA II shows modified dynamics of W2, His64, and EC waters as compared to Zn-CA II (Fig. 6f). Meanwhile, in Ni-CA II, octahedral coordination is stabilized throughout the entire catalytic cycle, and consequently, $\mathrm{W} 1$ is absent due to its steric hindrance with one of the Ni-bound water molecules (Figs. 2d, 5a, and $6 \mathrm{~g}$ ). Based on the $\mathrm{CO}_{2}$ binding configuration in $\mathrm{Zn}$-CA II and the bidentate $\mathrm{HCO}_{3}{ }^{-}$binding observed in Ni-CA II, it is most likely that the substrate-toproduct conversion occurs via the nucleophilic attack from $\mathrm{W}_{\mathrm{Ni}}{ }^{\prime}$ to $\mathrm{CO}_{2}$ (Fig. 5b). This result suggests that the proton transfer occurs possibly via the modified pathway $\mathrm{W}_{\mathrm{Ni}^{\prime}} \rightarrow \mathrm{W}_{\mathrm{Ni}} \rightarrow \mathrm{W} 2 \rightarrow$ His64 (Fig. 6g). Also, unlike Zn-CA II and Co-CA II, W2 in NiCA II shows significantly different dynamics and $\mathrm{W}_{\mathrm{I}}^{\prime}$ is destabilized, a plausible reflection of the altered electrostatic environment (Fig. 6h). Finally, Cu-CA II reveals that the possible proton transfer pathway ( $\left.\mathrm{W}_{\mathrm{Cu}} \rightarrow \mathrm{W} 1 \rightarrow \mathrm{W} 2 \rightarrow \mathrm{His64}\right)$ is welldefined (Fig. 6i) and W2 and His64 dynamics is surprisingly similar to that in Zn-CA II (Fig. 6j). This result corroborates well with our conjecture that it is the lack of efficient substrate binding and unfavorable distorted geometry for the nucleophilic attack that are responsible for the complete inactivity of $\mathrm{Cu}-\mathrm{CA}$ II.

\section{Discussion}

Our results provide advanced insights into the role of metal ions and the metal-protein relationship for the CA II catalytic mechanism. In the absence of metal ions, the protein scaffold provides a fundamental structural template necessary for the catalytic activity. The protein scaffold helps usher a substrate molecule from the outside bulk solvent into the active site through desolvating and positioning it at a configuration conducive for nucleophilic attack. The protein scaffold also provides well-ordered water networks in the vicinity of the active site, which can be utilized for proton transfer and substrate/product/ water exchange. Metal ions then bring a key property for the CA II catalytic activity in generating hydroxyl ion at neutral $\mathrm{pH}$ and retaining it at the active site. Beyond their primary Lewis acid property, metal ions are directly involved in the catalytic mechanism via their coordination geometry and long-range electrostatic effects. The most efficient native $\mathrm{Zn}$-CA II preserves a tetrahedral coordination and fine-tunes the water network embedded within the protein scaffold (Fig. 1c). The tetrahedral coordination allows efficient conversion of substrate into product, and the long-range electrostatic field orchestrates the structure and dynamics of water network in the active site, imperative for the rapid product displacement and fast proton transfer. In comparison, semi-efficient Co-CA II shows similar catalytic behavior up to the product formation stage as in Zn-CA II, but the expansion of the metal coordination geometry from tetrahedron to octahedron during the catalytic cycle alters the product displacement and proton transfer process (Fig. 7). The significantly less efficient Ni-CA II maintains octahedral coordination and shows altered electrostatic effects, hampering efficient conversion from substrate to product, product displacement, and proton transfer (Fig. 8). Finally, completely inactive Cu-CA II suggests substantial steric hindrance encountered by the substrate in the active site and poor geometry for product conversion due to the trigonal bipyramidal coordination (Fig. 9).

In conclusion, we examined the role of various metal ions in carbonic anhydrase catalysis beyond their primary chemical property as a Lewis acid. We demonstrated that metal ions are directly involved in the enzymatic mechanism via their coordination geometry and long-range electrostatics to orchestrate intricate water dynamics. Our experimental results can be used as direct input for theoretical and computational studies on the role of metal ions, which we anticipate could open a new window to the study of metal-protein relationships, drug discovery targeting metalloenzymes, engineering of natural metalloenzymes, rational design of de novo metalloenzymes, and synthesis of supramolecular analogues to metalloenzymes.

\section{Methods}

Protein expression and purification. The native $\mathrm{Zn}$-CA II was expressed in a recombinant strain of Escherichia coli [BL21 (DE3) pLysS] containing a plasmid encoding the CA II gene ${ }^{35}$. Purification was carried out using affinity chromatography ${ }^{36}$. Briefly, bacterial cells were enzymatically lysed with hen egg white lysozyme, and the lysate was placed onto an agarose resin coupled with $p$-(aminomethyl)-benzene-sulfonamide which binds CA II. The protein on the resin was eluted with $0.4 \mathrm{M}$ sodium azide, in $100 \mathrm{mM}$ Tris- $\mathrm{HCl} \mathrm{pH} \mathrm{7.0.} \mathrm{The} \mathrm{azide} \mathrm{was}$ removed by extensive buffer exchange against $10 \mathrm{mM}$ Tris- $\mathrm{HCl} \mathrm{pH} 8.0$.

Apo-CA II (zinc free) was then prepared by incubating $\mathrm{Zn}$-CA II in a zinc chelation buffer (100 mM pyridine 2,6-dicarboxylic acid, $25 \mathrm{mM}$ MOPS pH 7.0) at $20^{\circ} \mathrm{C}$ for $18 \mathrm{~h}$. The resulting protein was then run through an affinity column with benzylsulfonamide resin to remove residual $\mathrm{Zn}$-CA II. The chelating agent was then removed by buffer-exchange against $50 \mathrm{mM}$ Tris- $\mathrm{HCl} \mathrm{pH} 7.8^{18}$. The loss of zinc ion was examined using the esterase kinetic assay and further confirmed in the crystallographic structure. The enzyme activity was revived by an addition of $1 \mathrm{mM}$ $\mathrm{ZnCl}_{2}$.

Esterase kinetic assay. The $\mathrm{CO}_{2} / \mathrm{HCO}_{3}{ }^{-}$conversion catalytic activity of CA II can be measured directly by stopped flow assays, monitoring labeled $\mathrm{CO}_{2} / \mathrm{HCO}_{3}$ 
(1)<smiles></smiles>

(2)

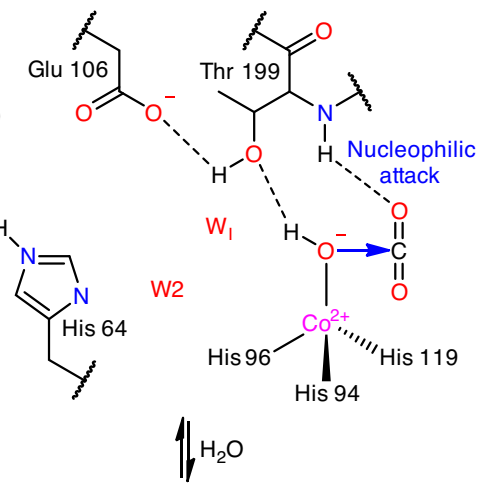

(3)<smiles>CCC(=O)C(C(C)OC[OH+]C(=O)CC(C)(Cl)Cl)N(CC)CC</smiles>

(4)

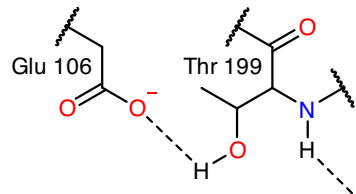<smiles>CCCc1cnc[nH]1</smiles>

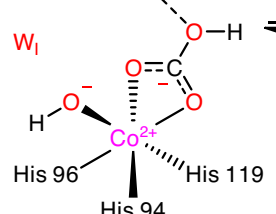
$w_{1}$<smiles>C=C=C</smiles>

Fig. 7 Proposed catalytic mechanism of Co-CA II. In Co-CA II, $\mathrm{CO}_{2}$ binding and the catalytic conversion of $\mathrm{CO}_{2}$ to $\mathrm{HCO}_{3}^{-}$occur in the same way as in the $\mathrm{Zn}-\mathrm{CA}$ II with tetrahedral geometry. However, the $\mathrm{HCO}_{3}{ }^{-}$displacement and proton transfer process are significantly altered due to the coordination expansion to octahedral geometry during catalysis. This octahedral coordination allows bidentate binding mode of $\mathrm{HCO}_{3}{ }^{-}$and reorganization of negative charge of $\mathrm{HCO}_{3}-$ toward $\mathrm{Co}^{2+}$ ion, allowing stronger $\mathrm{HCO}_{3}-$ binding to metal ion. To dissociate the product, proton transfer first occurs via an altered pathway (possibly, $\mathrm{W}_{\mathrm{Co}, \mathrm{octa}} \rightarrow \mathrm{W} 2 \rightarrow \mathrm{His64)}$ ) and $\mathrm{W}_{\mathrm{Co}, \text { octa }}$ is converted into the hydroxyl ion. This negatively charged hydroxyl ion then pushes away the bound product, and the tetrahedral coordination is restored for the next catalytic cycle.

(1)<smiles>CCCC1=CN(I)CN1</smiles>

(4)

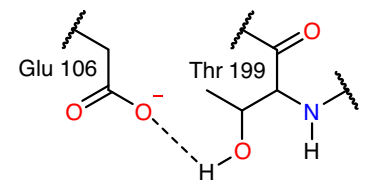

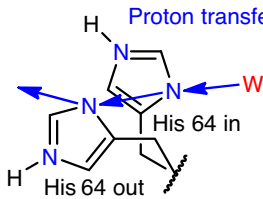

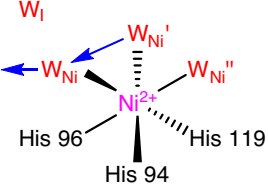

(2)<smiles></smiles>

(3)<smiles>CCCc1cn(C)cn1</smiles>

Fig. 8 Proposed catalytic mechanism of Ni-CA II. In Ni-CA II, octahedral coordination is maintained throughout the whole catalytic cycle. The significant consequence is that one of the three bound water molecules experiences steric hindrance with the $\mathrm{CO}_{2}$ binding. In addition, the nucleophilic attack geometry is distorted (Fig. 5b), suggesting less efficient conversion into $\mathrm{HCO}_{3}{ }^{-}$. The formed $\mathrm{HCO}_{3}{ }^{-}$is strongly bound to $\mathrm{Ni}^{2+}$ ion in a bidentate mode as in the Co-CA II but is directly displaced by two inflowing water molecules. Finally, proton transfer occurs via an altered network (possibly, $\mathrm{W}_{\mathrm{Ni}}{ }^{\prime} \rightarrow \mathrm{W}_{\mathrm{Ni}} \rightarrow$ W2 $\rightarrow$ His64) to restore the catalytic cycle. 


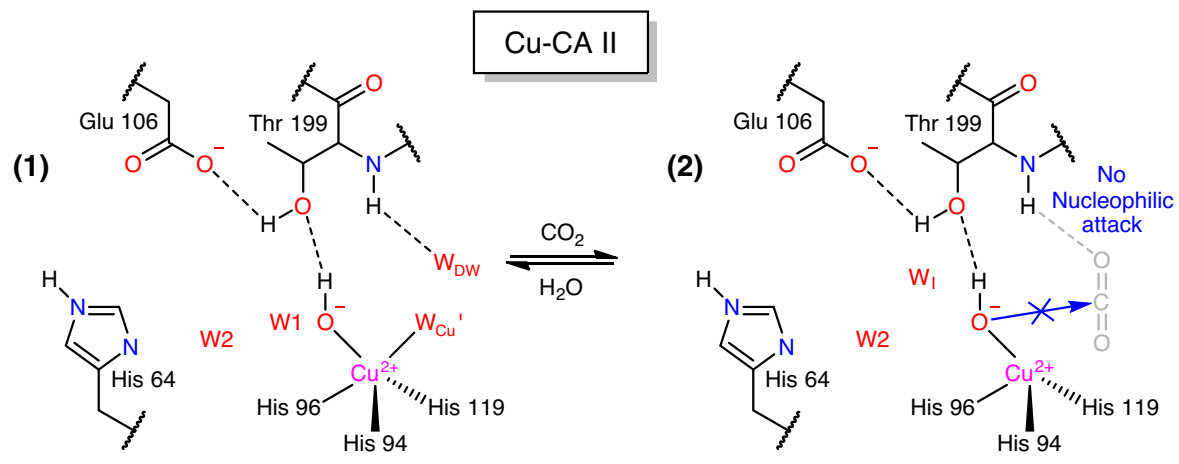

Fig. 9 Proposed catalytic mechanism of Cu-CA II. In Cu-CA II, one of the two bound water molecules in the trigonal bipyramid coordination experiences significant steric hindrance from $\mathrm{CO}_{2}$ molecule, hindering adoption of proper configuration for nucleophilic attack. In addition, even if $\mathrm{CO}_{2}$ binds to the active site temporarily, the nucleophilic attack geometry is too distant (3.9 $\AA$ ) and significantly distorted (Fig. $5 \mathrm{~d}$ ).

conversion using mass spectroscopy, or indirectly by monitoring the innate esterase activity spectroscopically ${ }^{37,38}$. In this study, the esterase activity assays were performed as a control to ensure zinc was fully chelated from recombinant CA II. The 4nitrophenyl acetate (4-NPA) molecule is cleavable by CA II and thus used here as a colorimetric substrate. CA II cleaves the ester bond of 4-NPA generating 4-nitrophenol, which is spectroscopically absorbent at $348 \mathrm{~nm}$ in the ultraviolet-visible spectrum. Thus, the reaction can be monitored spectroscopically at $348 \mathrm{~nm}^{39}$.

In a 96 deep-well plate, aliquots of $50 \mu \mathrm{L}$ of $0.1 \mathrm{mg} \mathrm{mL}^{-1} \mathrm{CA}$ II in storage buffer were added to each well. To initiate the reaction, $200 \mu \mathrm{L}$ of $0.8 \mathrm{mM} 4$-NPA dissolved in $3 \%$ acetone in water was added to the sample well. The well plate was then immediately inserted into the plate reader (Synergy HTX, BioTek, Winooski, WI, USA). Absorbance at $348 \mathrm{~nm}$ was recorded every $8 \mathrm{~s}$ for $10 \mathrm{~min}$. The absorbance data of Apo- and Zn-CA II are plotted in Supplementary Fig. 4.

Crystallization and non-native metal substitution. Crystals of CA II were obtained using the hanging drop vapor diffusion $\operatorname{method}^{40}$. A $10 \mu \mathrm{l}$ drop of equal volumes of protein $(5 \mu \mathrm{l})$ and the well-solution $(5 \mu \mathrm{l})$ was equilibrated against 500 $\mu \mathrm{l}$ of the well-solution ( $1.3 \mathrm{M}$ sodium citrate, $50 \mathrm{mM}$ Tris- $\mathrm{HCl} \mathrm{pH} \mathrm{7.8)}$ at RT $\left(\sim 20^{\circ}\right.$ C $)^{41}$. Crystals grew to an approximate $\sim 30 \times 100 \times 200 \mu \mathrm{m}^{3}$ in size in a few days. To prepare non-native metal substituted CA II, the apo-CA II crystals were transferred into soaking solutions of cobalt, nickel and copper salt $\left(100 \mathrm{mM} \mathrm{CoCl}_{2}\right.$, $100 \mathrm{mM} \mathrm{NiCl}_{2}, 10 \mathrm{mM} \mathrm{CuCl}_{2}$ along with $1.3 \mathrm{M}$ sodium citrate, $50 \mathrm{mM}$ Tris- $\mathrm{HCl}$ with $\mathrm{pH}$ 7.8). The crystals were incubated for $2-3$ days to let the $\mathrm{Co}^{2+}, \mathrm{Ni}^{2+}$ and $\mathrm{Cu}^{2+}$ ions infuse into the active site ${ }^{42}$. The CA II crystals at $\mathrm{pH} 11.0$ were obtained with 3-(cyclohexylamino)propanesulfonic acid buffer instead of using Tris- $\mathrm{HCl}$.

Cryocooling under $\mathrm{CO}_{2}$ pressure. Cryo-trapping the intermediate states of $\mathrm{Zn}-\mathrm{CA}$ II was previously achieved by cryocooling CA II crystals under $\mathrm{CO}_{2}$ pressure ${ }^{33,34}$, leading to the capture of $\mathrm{CO}_{2}$ in the active site of $\mathrm{CA} \mathrm{II}{ }^{43}$. More recently, series of intermediate states have been tracked in CA II by controlling the internal $\mathrm{CO}_{2}$ pressure levels ${ }^{25,44}$. In this study, the $\mathrm{CO}_{2}$ entrapment was carried out using a highpressure cryo-cooler for X-ray crystallography (HPC-201, Advanced Design Consulting, USA). The apo-, Zn-, Co-, Ni-, and Cu-CA II crystals were first soaked in a cryo-solution containing $35 \%(\mathrm{v} / \mathrm{v})$ glycerol supplemented to the soaking solution. The crystals were then coated with mineral oil to prevent dehydration, and loaded into the base of high-pressure tubes ${ }^{33}$. The coated mineral oil worked as a $\mathrm{CO}_{2}$ buffering medium as well, aiding in the absorption of $\mathrm{CO}_{2}$ into the crystals ${ }^{45}$. The crystals were pressurized at room temperature in the pressure tubes with $\mathrm{CO}_{2}$ gas at 0 $\mathrm{atm}$ (no pressurization) and $20 \mathrm{~atm}$. After a wait of about $5 \mathrm{~min}$, the crystals were cryocooled in liquid nitrogen $(77 \mathrm{~K})$. Once the $\mathrm{CO}_{2}$ bound crystals were fully cryocooled, the $\mathrm{CO}_{2}$ gas pressure was withdrawn, and the crystal samples were stored in a liquid nitrogen dewar for subsequent X-ray data collection.

X-ray diffraction and data collection. Diffraction data were collected at Pohang Light Source II (wavelength of $0.9793 \AA$, beam size of $100 \mu \mathrm{m}$ ) under nitrogen cold stream $(100 \mathrm{~K})$. Data were collected using the oscillation method in intervals of $1^{\circ}$ step on an ADSC Quantum 270 CCD detector (Area Detector Systems Corporation, USA) with a crystal-to-detector distance of $120 \mathrm{~mm}$. A total of 360 images were collected on each of the CA II crystal data sets.

For each data set, a new fresh pressure-cryocooled crystal was used. The absorbed $\mathrm{X}$-ray dose for a single data set was less than $5 \times 10^{5} \mathrm{~Gy}$, which is much less than the Henderson dose limit of $1.2 \times 10^{7} \mathrm{~Gy}^{46}$. Moreover, we have checked that X-ray radiation dose at least up to $10^{7} \mathrm{~Gy}$ does not induce apparent changes in the active site. The result confirms that the active site structures described in our study are unaffected by the X-ray radiation. Indexing, integration, and scaling were performed by using HKL2000 ${ }^{47}$. The data processing statistics are given in Supplementary Table 1.
Structure determination and model refinement. The CA II structures were determined using the CCP4 program suite ${ }^{48}$. Prior to refinement, a random $5 \%$ of the data were flagged for $R_{\text {free }}$ analysis. The previously reported crystal structures (PDB codes of 5DSR and 5YUK for apo- and metal substituted CA II) were used as the initial phasing models 25,49 . The maximum likelihood refinement (MLH) was carried out using REFMAC $5^{50}$. The refined structures were manually checked using the molecular graphics program $\mathrm{COOT}^{51}$. Reiterations of MLH were carried out with anisotropic B factor.

On completion of the structural refinements as described above, systematic refinements were further carried out to accurately determine the partial occupancies of the His 64 in and the His 64 out configurations. A total of 99 structures were prepared for each of the CA II structures, in which the occupancies of the His 64 in and the His 64 out configurations were changed in incremental steps of $1 \%$ (i.e., the first structure with $1 \%$ in and $99 \%$ out, the second structure with $2 \%$ in and $98 \%$ out, ..., the 99 th structure with $99 \%$ in and $1 \%$ out). MLH refinements were carried out in parallel for all the 99 structures. After MLH refinements, the overall $R$-factor as a function of partial occupancy of the His 64 in configuration was obtained, and it was fitted into a quadratic function (Supplementary Fig. 5). The partial occupancy values of the His 64 configurations were determined where the overall R-factor is minimized. Details on the final refinement statistics are given in Supplementary Table 1. All structural figures were rendered with PyMol (Schrödinger, LLC).

Structural analysis of the bound water molecules. To compare the bound water molecules in the active site and the EC, we carefully refined water molecules based on the PDB and COOT validation checks and the electron density maps (cutoff level of $1 \sigma$ in $2 \mathrm{~F}_{\mathrm{o}}-\mathrm{F}_{\mathrm{c}}$ electron density map). We have tested the consistency and reproducibility of the bound water molecules in the active site and the EC carefully. There were several closely positioned water molecules in the active site and the EC of the CA II structures. Since most of these waters exist transiently, it was allowed that they can be located closer than the normal stably bound water molecules. In this regard, water molecules closely located near the active site and EC regions were not excluded in the final coordinates. The important bound water molecules addressed in the main paper are listed in Supplementary Table 2. The distance information between $\mathrm{CO}_{2}, \mathrm{HCO}_{3}{ }^{-}$, Thr199, and important water molecules is listed in Supplementary Table 3.

Reporting summary. Further information on research design is available in the Nature Research Reporting Summary linked to this article.

\section{Data availability}

The atomic coordinates and structure factors have been deposited in the Protein Data Bank (http://wwpdb.org/) as [PDB code 6LUU [https://doi.org/10.2210/pdb6luu/pdb] (0 atm $\mathrm{CO}_{2}$ pressure, $\mathrm{pH} 7.8$ ), 6LUV [https://doi.org/10.2210/pdb6luv/pdb] (20 atm, pH 7.8)] for apo-CA II, [6LUW [https://doi.org/10.2210/pdb6luw/pdb] (0 atm, pH 7.8), 6LUX [https://doi.org/10.2210/pdb6lux/pdb] (20 atm, pH 7.8), 6LUY [https://doi.org/ 10.2210/pdb6luy/pdb] (0 atm, pH 11.0), 6LUZ [https://doi.org/10.2210/pdb6luz/pdb] (20 atm, pH 11.0)] for Zn-CA II, [6LV1 [https://doi.org/10.2210/pdb6lv1/pdb] (0 atm, pH 7.8), 6LV2 [https://doi.org/10.2210/pdb6lv2/pdb] (20 atm, pH 7.8), 6LV3 [https://doi. org/10.2210/pdb6lv3/pdb] (0 atm, pH 11.0), 6LV4 [https://doi.org/10.2210/pdb6lv4/pdb] (20 atm, pH 11.0)] for Co-CA II, [6LV5 [https://doi.org/10.2210/pdb6lv5/pdb] (0 atm, pH 7.8), 6LV6 [https://doi.org/10.2210/pdb6lv6/pdb] (20 atm, pH 7.8), 6LV7 [https://doi. org/10.2210/pdb6lv7/pdb] (0 atm, pH 11.0), 6LV8 [https://doi.org/10.2210/pdb6lv8/pdb] (20 atm, pH 11.0)] for Ni-CA II, and [6LV9 [https://doi.org/10.2210/pdb6lv9/pdb] (0 atm, pH 7.8), 6LVA [https://doi.org/10.2210/pdb6lva/pdb] (20 atm, pH 7.8)] for Cu-CA II. Two earlier structures [5DSR [https://doi.org/10.2210/pdb5dsr/pdb] and 5YUK 
[https://doi.org/10.2210/pdb5yuk/pdb]] were used for structure determination. Source data are provided with this paper.

Received: 21 March 2020; Accepted: 20 August 2020;

Published online: 11 September 2020

\section{References}

1. Lippard, S. J. \& Berg, J. M. Principles of Bioinorganic Chemistry 70 (University Science Books Mill Valley, CA, 1994).

2. Holm, R. H., Kennepohl, P. \& Solomon, E. I. Structural and functional aspects of metal sites in biology. Chem. Rev. 96, 2239-2314 (1996).

3. Ragsdale, S. W. Metals and their scaffolds to promote difficult enzymatic reactions. Chem. Rev. 106, 3317-3337 (2006).

4. Liu, J. et al. Metalloproteins containing cytochrome, iron-sulfur, or copper redox centers. Chem. Rev. 114, 4366-4469 (2014).

5. Rulisek, L. \& Vondrasek, J. Coordination geometries of selected transition metal ions $(\mathrm{Co} 2+, \mathrm{Ni} 2+, \mathrm{Cu} 2+, \mathrm{Zn} 2+, \mathrm{Cd} 2+$, and $\mathrm{Hg} 2+)$ in metalloproteins. J. Inorg. Biochem. 71, 115-127 (1998).

6. Dudev, T. \& Lim, C. Principles governing $\mathrm{Mg}, \mathrm{Ca}$, and $\mathrm{Zn}$ binding and selectivity in proteins. Chem. Rev. 103, 773-788 (2003).

7. Parr, R. G. \& Pearson, R. G. Absolute hardness-companion parameter to absolute electronegativity. J. Am. Chem. Soc. 105, 7512-7516 (1983).

8. Irving, H. \& Williams, R. J. P. Order of stability of metal complexes. Nature 162, 746-747 (1948).

9. Sigel, H. \& Mccormic, D. B. On discriminating behavior of metal ions and ligands with regard to their biological significance. Acc. Chem. Res. 3, 201 (1970).

10. Parkin, G. Synthetic analogues relevant to the structure and function of zinc enzymes. Chem. Rev. 104, 699-767 (2004).

11. Valdez, C. E., Smith, Q. A., Nechay, M. R. \& Alexandrova, A. N. Mysteries of metals in metalloenzymes. Acc. Chem. Res 47, 3110-3117 (2014).

12. Spiro, T. G. Zinc Enzymes. (J. Wiley New York, 1983).

13. Davenport, H. W. The early days of research on carbonic anhydrase. Ann. N. Y. Acad. Sci. 429, 4-9 (1984).

14. Chegwidden, W. R., Carter, N. D. \& Edwards, Y. H. The Carbonic Anhydrases: New Horizons. Vol. 90 (Birkhäuser, 2013).

15. Frost, S. C. \& McKenna, R. Carbonic Anhydrase: Mechanism, Regulation, Links to Disease, and Industrial Applications. Vol. 75 (Springer Science \& Business Media, 2013).

16. Supuran, C. T. \& De Simone, G. Carbonic anhydrases as biocatalysts: from theory to medical and industrial applications. (Elsevier, 2015).

17. Liang, J. Y. \& Lipscomb, W. N. Theoretical-study of carbonic anhydrasecatalyzed hydration of $\mathrm{Co} 2-$ a brief review. Int. J. Quantum Chem. 36, 299-312 (1989).

18. Håkansson, K., Carlsson, M., Svensson, L. A. \& Liljas, A. Structure of native and apo carbonic anhydrase II and structure of some of its anion-ligand complexes. J. Mol. Biol. 227, 1192-1204 (1992).

19. Lindskog, S. \& Silverman, D. N. in The Carbonic Anhydrases 175-195 (Springer, 2000).

20. Silverman, D. N. \& McKenna, R. Solvent-mediated proton transfer in catalysis by carbonic anhydrase. Acc. Chem. Res. 40, 669-675 (2007).

21. Krishnamurthy, V. M. et al. Carbonic anhydrase as a model for biophysical and physical-organic studies of proteins and protein-ligand binding. Chem. Rev. 108, 946-1051 (2008).

22. Liljas, A. et al. Crystal structure of human carbonic anhydrase C. Nat. N. Biol. 235, 131-137 (1972).

23. Eriksson, A., Kylsten, P., Jones, T. \& Liljas, A. Proteins: structures and functions. Genetics 4, 283-293 (1988).

24. Christianson, D. W. \& Fierke, C. A. Carbonic anhydrase: evolution of the zinc binding site by nature and by design. Acc. Chem. Res. 29, 331-339 (1996).

25. Kim, J. K. et al. Active-site solvent replenishment observed during human carbonic anhydrase II catalysis. IUCrJ 5, 93-102 (2018).

26. McCall, K. A., Huang, C. \& Fierke, C. A. Function and mechanism of zinc metalloenzymes. J. Nutr. 130, 1437S-1446S (2000).

27. Piazzetta, P., Marino, T., Russo, N. \& Salahub, D. R. The role of metal substitution in the promiscuity of natural and artificial carbonic anhydrases. Coord. Chem. Rev. 345, 73-85 (2017).

28. Andring, J. T., Kim, C. U. \& McKenna, R. Structure and mechanism of copper-carbonic anhydrase II: a nitrite reductase. IUCrJ 7, 287-293 (2020).

29. Hakansson, K. \& Wehnert, A. Structure of cobalt carbonic anhydrase complexed with bicarbonate. J. Mol. Biol. 228, 1212-1218 (1992).

30. Hakansson, K., Wehnert, A. \& Liljas, A. X-ray analysis of metal-substituted human carbonic anhydrase II derivatives. Acta Crystallogr. D Biol. Crystallogr. 50, 93-100 (1994).
31. Lindskog, S. \& Nyman, P. O. Metal-binding properties of human erythrocyte carbonic anhydrases. Biochim. Biophys. Acta 85, 462-474 (1964).

32. Coleman, J. E. Metal ion dependent binding of sulphonamide to carbonic anhydrase. Nature 214, 193-194 (1967).

33. Kim, C. U., Kapfer, R. \& Gruner, S. M. High-pressure cooling of protein crystals without cryoprotectants. Acta Crystallogr. Sect. D Biol. Crystallogr. 61, 881-890 (2005)

34. Kim, C. U., Wierman, J. L., Gillilan, R., Lima, E. \& Gruner, S. M. A highpressure cryocooling method for protein crystals and biological samples with reduced background X-ray scatter. J. Appl. Crystallogr. 46, 234-241 (2013).

35. Forsman, C., Behravan, G., Osterman, A. \& Jonsson, B.-H. Production of active human carbonic anhydrase 11 in E. coli. Acta Chem. Scand. 42, 314-318 (1988).

36. Khalifah, R. G., Strader, D. J., Bryant, S. H. \& Gibson, S. M. Carbon-13 nuclear magnetic resonance probe of active-site ionizations in human carbonic anhydrase B. Biochemistry 16, 2241-2247 (1977).

37. Coleman, J. E. Mechanism of action of carbonic anhydrase-substrate sulfonamide and anion binding. J. Biol. Chem. 242, 5212-5219 (1967).

38. Tu, C. \& Silverman, D. Catalysis of cobalt (II)-substituted carbonic anhydrase II of the exchange of oxygen-18 between carbon dioxide and water. Biochemistry 24, 5881-5887 (1985).

39. Tashian, R. E., Douglas, D. P. \& Yu, Y. S. Esterase and hydrase activity of carbonic anhydrase. I. From primate erythrocytes. Biochem. Biophys. Res. Commun. 14, 256-261 (1964).

40. McPherson, A. Preparation and Analysis of Protein Crystals. (John Wiley \& Sons, 1982).

41. Fisher, S. Z. et al. Atomic crystal and molecular dynamics simulation structures of human carbonic anhydrase II: insights into the proton transfer mechanism. Biochemistry 46, 2930-2937 (2007).

42. Avvaru, B. S. et al. Comparison of solution and crystal properties of Co(II)substituted human carbonic anhydrase II. Arch. Biochem. Biophys. 502, 53-59 (2010).

43. Domsic, J. F. et al. Entrapment of carbon dioxide in the active site of carbonic anhydrase II. J. Biol. Chem. 283, 30766-30771 (2008).

44. Kim, C. U. et al. Tracking solvent and protein movement during $\mathrm{CO}_{2}$ release in carbonic anhydrase II crystals. Proc. Natl Acad. Sci. USA 113, 5257-5262 (2016).

45. Kim, C. U., Hao, Q. \& Gruner, S. M. Solution of protein crystallographic structures by high-pressure cryocooling and noble-gas phasing. Acta Crystallogr. D Biol. Crystallogr. 62, 687-694 (2006).

46. Henderson, R. Cryo-protection of protein crystals against radiation damage in electron and X-ray diffraction. Proc. R. Soc. B 241, 6-8 (1990).

47. Otwinowski, Z. \& Minor, W. Processing of X-ray diffraction data collected in oscillation mode. Methods Enzymol. 276, 307-326 (1997).

48. Collaborative, C. P. The CCP4 suite: programs for protein crystallography. Acta Crystallogr. Sect. D Biol. Crystallogr. 50, 760 (1994).

49. West, D. et al. Structural and kinetic effects on changes in the $\mathrm{CO}(2)$ binding pocket of human carbonic anhydrase II. Biochemistry 51, 9156-9163 (2012).

50. Murshudov, G. N., Vagin, A. A. \& Dodson, E. J. Refinement of macromolecular structures by the maximum-likelihood method. Acta Crystallogr. D Biol. Crystallogr. 53, 240-255 (1997).

51. Emsley, P. \& Cowtan, K. Coot: model-building tools for molecular graphics. Acta Crystallogr. D Biol. Crystallogr. 60, 2126-2132 (2004).

52. Krebs, J. F., Ippolito, J. A., Christianson, D. W. \& Fierke, C. A. Structural and functional importance of a conserved hydrogen bond network in human carbonic anhydrase II. J. Biol. Chem. 268, 27458-27466 (1993).

53. Xue, Y., Liljas, A., Jonsson, B. H. \& Lindskog, S. Structural analysis of the zinc hydroxide-Thr-199-Glu-106 hydrogen-bond network in human carbonic anhydrase II. Proteins 17, 93-106 (1993).

54. Liljas, A. Carbonic anhydrase under pressure. IUCrJ 5, 4-5 (2018).

\section{Acknowledgements}

The authors would like to thank the staff at Pohang Light Source II for their support in data collection. This work was initiated by the support of Samsung Science and Technology Foundation (SSTF-BA1702-04) and further supported by the National Research Foundation of Korea (NRF) grant (NRF-2019R1A2C1004274) funded by the Korea government (MSIT).

\section{Author contributions}

C.U.K. conceived the research, J.K.K., C.L., S.W.L., J.T.A. ran the experiments, J.K.K. and C.U.K. analysed the data. J.K.K., A.A., R.M., C.-M.G., and C.U.K. wrote the paper. All authors contributed to the overall scientific interpretation and edited the paper.

\section{Competing interests}

The authors declare no competing interests. 


\section{Additional information}

Supplementary information is available for this paper at https://doi.org/10.1038/s41467020-18425-5.

Correspondence and requests for materials should be addressed to C.U.K.

Peer review information Nature Communications thanks Ian Davis and the other, anonymous reviewer(s) for their contribution to the peer review of this week. Peer review reports are available.

Reprints and permission information is available at http://www.nature.com/reprints

Publisher's note Springer Nature remains neutral with regard to jurisdictional claims in published maps and institutional affiliations. (c) (i) Open Access This article is licensed under a Creative Commons Attribution 4.0 International License, which permits use, sharing, adaptation, distribution and reproduction in any medium or format, as long as you give appropriate credit to the original author(s) and the source, provide a link to the Creative Commons license, and indicate if changes were made. The images or other third party material in this article are included in the article's Creative Commons license, unless indicated otherwise in a credit line to the material. If material is not included in the article's Creative Commons license and your intended use is not permitted by statutory regulation or exceeds the permitted use, you will need to obtain permission directly from the copyright holder. To view a copy of this license, visit http://creativecommons.org/ licenses/by/4.0/.

(C) The Author(s) 2020 